\title{
Are Indonesians sensitive to contrastive accentuation below the word level?
}

\author{
VINCENT J. VAN HEUVEN AND VERA FAUST
}

\begin{abstract}
It is impossible in Indonesian to express narrow-focus meta-linguistic contrasts on subparts of words (whether meaningless syllables or meaningful morphemes). In English and Dutch this possibility exists, as in I meant coffIN not cofrER or I said meaningfuL not meaningLESS. We predict from this circumstance that Indonesian learners of Dutch will not be sensitive to this type of prosodic contrast marking at the sub-word level. Native Dutch speakers should be able to make functional use of this type of contrast. We conducted an experiment with thirteen Indonesian learners of Dutch with lengths of residence in the Netherlands between 3 weeks and 27 years, and a group of thirteen native Dutch speakers as controls. The results show that the Indonesian learners perform at chance level, and are therefore insensitive to narrow-focus contrasts below the word level. Dutch learners are highly sensitive to these contrasts on average, although three out of thirteen performed at chance level. We argue from these results that Indonesian has no word stress.
\end{abstract}

KEYWORDS

Accent, Dutch, focus, Indonesian, meta-linguistic contrast, second-language acquisition of prosodic functions, stress, word-prosodic typology.

\section{INTRODUCTION}

\subsection{TYPOLOGY OF WORD-PROSODIC SYSTEMS}

The languages in the world can be divided roughly into having two types of word-prosodic systems. The first type, probably a minority, has tone. ${ }^{1}$ In

1 The World Atlas of Linguistic Structures (WALS, Comrie, Dryer, Haspelmath, and Gil 2005) lists 220 tone languages versus 307 no-tone languages (Chapter 13); at the same time

VINCENT J. VAN HEUVEN is professor of Experimental Linguistics and Phonetics at the Leiden University Centre for Linguistics, and former director of the institute. He is a member of the Royal Netherlands Academy of Arts and Sciences, secretary to the Permanent Council of the IPA, and associate editor of Phonetica. E-mail: V.J.J.P.van.heuven@hum.leidenuniv.nl.

VERA FAUST obtained her Master's degree in Asian Area Studies from Leiden University in 2006, specializing in descriptive linguistics in Austronesian languages.

(C) 2009 Fakultas Ilmu Pengetahuan Budaya, Universitas Indonesia 
a tone language, different pitches or melodies may be used to differentiate between words in the lexicon, just as the vowels and the consonants do. The second type, which is the type that we address in the present article, has stress. When a language has stress, every word has one syllable, which in some sense is more important, or more prominent, than any other syllable in the same word. This is also the crucial difference between tone and stress; in a tone language, there is no difference in prominence attached to the syllables that make up the word, whereas stress is a culminative property: only one syllable can be the strongest. It appears that the two types of word prosody are mutually exclusive. A language has either tone or stress but not both. To be true, there are so-called restricted tone languages in which only one syllable in a word may carry different tones (for example, Swedish, Norwegian) but languages that freely combine stress and tone are highly exceptional and may arise only as the result of accidental contact between a stress language and a tone language such as Samate Mâya (Remijsen 2002) or Papiamentu (Remijsen and Van Heuven 2005).

The fourth logical possibility is a language that has neither stress nor tone. Such languages are also rare. Recently it has been argued that Indonesian would be one such language. Although there is a widespread belief that Indonesian is a language with fixed stress on the penultimate syllable (for a survey of positions see Odé 1994), there is substantial evidence that Indonesian speakers produce the same word with variable stress position (Van Heuven, Roosman, and Van Zanten 2008) and that Indonesian listeners accept stress in almost any position in the word (Van Zanten, Goedemans, and Pacilly 2003; Van Zanten and Goedemans 2007). We also know that Indonesian listeners do not use stress as a source of information in the word recognition process, which is what we would expect if stress is not part of the phonological specification of a word (Van Zanten and Van Heuven 1998, 2004). In stress-language such as Dutch, however, stress is used in the process of word recognition to narrow down the pool of recognition candidates (Van Heuven 1988, 2009; Cutler and Van Donselaar 2001). Moreover, if Dutch or English words are stressed on the wrong syllable, word recognition is compromized (Van Heuven 2009 for Dutch; Cutler and Clifton 1984 for English).

Dutch is a language in which each polysyllabic word is pronounced with stress on one specific syllable. The position of the stressed syllable is highly predictable from a small set of weight-sensitive rules. Langeweg (1988) shows that about 85 percent of the Dutch monomorphemic vocabulary has regular stress; the remaining 15 percent has stress in exceptional syllable positions; the stress patterns of such words have to be stored separately in the lexicon (so-called lexical stress). In weight-sensitive languages such as English and Dutch, the sounds in a stressed syllable are pronounced with greater effort,

it lists 502 stress languages, divided in Chapter 14 between 282 with fixed stress (281 in Chapter 15) versus 220 with no-fixed stress (219 in Chapter 15). Van Zanten and Goedemans (2007: 64) estimate that languages with stress-based word prosody, tone-based systems and languages without word prosody occur in 80,16 , and $4 \%$ of the world's languages, respectively. 
which results in (i) longer duration, (ii) more extreme articulatory positions (spectral expansion of vowels), (iii) greater loudness (higher intensity and flatter spectral tilt) and (iv) more resistant to coarticulation.

\subsection{ACCENTUAL MARKING OF FOCUS}

When, in English or Dutch, a word is communicatively important ("in focus") in the discourse (depending on the intentions of the speaker) the stressed syllable in the word is additionally marked by a conspicuous change in vocal pitch (a rise, fall, or both). This pitch movement, also called "accent", is aligned with the stressed syllable in the word, which is therefore the prosodic head of the word. It is a general principle that a pitch movement (accent) on the prosodic head of a prosodic constituent, puts the entire constituent in focus, namely presents the entire constituent as important information for the listener. This is called "broad focus"; the accent is in the default position. In (1) the accent on man (indicated by small caps) marks the entire constituent the old man as in focus (indicated by square brackets), to be contrasted with the girl:

(1) Is Lesley [the GIRL] or [the old MAN]?

When only part of the higher constituent has to be interpreted as containing important information ("narrow focus"), the accent may be placed on a syllable that is not in the default accent position, namely which is not the prosodic head of the larger constituent. In (2) the accent on old can only be interpreted as making the adjective important; the focus domain does not also include man, since the contrast is between the adjectives young versus old; that the discourse is about men, is contextually given and therefore out of focus):

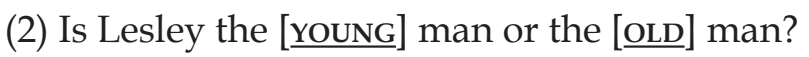

Interestingly, if the accent is in the default position, it is impossible to know without further context whether the focus is broad as in (1) or narrow as in (3) where the contrast is between the nouns and not between the adjectives:

(3) Is Lesley the old [woman] or the old [MAN]?

This system of accentual marking of narrow focus does not work in all languages. Ladd (1996) remarks that narrow focus contrasts on adjectives do not attract the accent, which remains on the constant noun instead as in (4):

(4) Quieren Usted café [con] LEEche o café [sin] LEche? 'Require you coffee [with] MILK or coffee [without] MILK?'

Ebing (1997) presents anecdotal evidence that contrast marking in Indonesian resembles the system used in Spanish, that is, keeps the accent on the prosodic 
head of the higher constituent (the noun phrase) and consequently differs from the narrow-focus driven accentuation used in Dutch and English.

In languages such as Dutch and English (and probably all Germanic languages) the system of marking contrast through accentuation of narrow focus may also be applied to contrasts below the word level. For example, in (5a), the word coffin is placed in focus by a default accent on its prosodic head, that is the first syllable. In (5b), however, the speaker wants to correct a misunderstanding and places narrow focus on the second syllable, which contains the segments that differ between the correct and incorrect alternatives in the contrast. The narrow focus is realized as an accent on second syllable, even though this syllable is not the prosodic of the word. It has been shown by Sluijter and Van Heuven $(1995,1996)$ that such narrow focus accents below the word level assume all the phonetic characteristics of a stressed and accent syllable, so that not only the melody but also the duration and the intensity characteristics suggest a prominence shift.

(5) a. John made a [Box] not a [ㅇfin]

b. I did not say cof[트], I said cof[EIN]

Ebing (1997) reports an informal experiment, in which he asked Indonesian speakers to produce contrastive accents on Indonesian materials as illustrated in $(6 a-b)$ constructed like $(5 b)$ :

(6) a. maksud saya çari bukan $\underline{\text { curi }}$

'intention mine seek not steal'

b. maksud saya can bukan catAT

'intention mine seek not note-down

His speakers had no idea what was expected of them. Moreover, when Indonesian listeners were subsequently asked to decide whether the accentuation of one syllable or another suggested a contrast between words or between syllables, they did not understand the difference, and when pushed hard, made random decisions.

\subsection{AIM OF THIS ARTICLE}

The aim of the present article is to provide one more piece of evidence in support of the hypothesis that Indonesian has no word stress. Our reasoning is as follows. If a language has no word stress but does use pitch movements (accents) at the phrase level to mark words for focus, the position of the accent within the word is irrelevant and accent has no communicative import other than making the entire word focused. The accentuation of one particular syllable cannot be used to place that specific syllable (rather than the whole word) in narrow focus, for instance to metalinguistically correct a misunderstanding as in (5b).

We know that in second-language learning it is very hard to relinquish 
one's native-language habits and replace these by the appropriate sound structures of the second language. This is especially difficult when it comes to prosody (for example, Chun 2002; Roosman 2006: 3-5; Rasier and Hilligsman 2007). We predict, accordingly, that it will be very difficult, if not impossible, for Indonesian learners of Dutch to get tuned into the system of using accents on syllables that are not the prosodic head of the word in order to correct misunderstandings below the word level. Specifically, we will test the hypothesis that Indonesian learners of Dutch will not be able to use the difference in accent position in words like coffin to decide whether a contrast is at the word level (as between COFfin versus BOX, in 5a) or at the sub-word level (as between COfFIN versus COfFER, in $5 b$ ).

We will test the hypothesis in a perception experiment. As far as we have been able to ascertain, the interpretation of contrastive accents on non-head syllables has never been tested for Dutch or English, either. Our experiment will therefore not only include Indonesian learners of Dutch as an experimental group but also a group of native Dutch listeners as controls.

If we should find that Indonesian learners cannot use the sub-word contrastive accentuation in Dutch, and if we find at the same time that these contrasts are used adequately by native Dutch listeners, we will take this as support for our claim that Indonesian has no stress at the word level.

\section{Methods}

\subsection{STIMULUS MATERIALS}

Ten word triplets were selected from the Dutch lexicon, such that each pair shared one syllable (or morpheme) but differed in the other one. Table 1 lists the ten triplets.

\begin{tabular}{|c|c|c|c|c|}
\hline & \multicolumn{2}{|c|}{ (a) Contrast in first syllable } & \multicolumn{2}{|c|}{ (b) Contrast in second syllable } \\
\hline 1. & $\begin{array}{l}\text { sPatie 'space' } \\
\text { /'spatsi/ }\end{array}$ & $\begin{array}{l}\text { GRAtie 'grace' } \\
\text { /'rratsi/ }\end{array}$ & $\begin{array}{l}\text { spatie } \\
\text { /'spatsi/ }\end{array}$ & $\begin{array}{l}\text { spatel 'spatula' } \\
\text { /'spatəl/ }\end{array}$ \\
\hline 2. & $\begin{array}{l}\text { KAter 'tomcat' } \\
\text { /'katər/ }\end{array}$ & $\begin{array}{l}\text { water 'id.' } \\
\text { /'watər/ }\end{array}$ & $\begin{array}{l}\text { kaTER } \\
\text { /'katər/ }\end{array}$ & $\begin{array}{l}\text { kamer 'room' } \\
\text { /'kamər/ }\end{array}$ \\
\hline 3. & $\begin{array}{l}\text { RuIsen 'rustle' } \\
\text { /'rœysən/ }\end{array}$ & $\begin{array}{l}\text { BRUIsen '???' } \\
\text { /'brœysən/ }\end{array}$ & $\begin{array}{l}\text { ruisen } \\
\text { /'roysən/ }\end{array}$ & $\begin{array}{l}\text { ruikeN 'smell' } \\
\text { /'roykən/ }\end{array}$ \\
\hline 4. & $\begin{array}{l}\text { RIOol 'sewer' } \\
\text { / ri'ol/ }\end{array}$ & $\begin{array}{l}\text { viool 'violin' } \\
\text { /vi'ol/ }\end{array}$ & $\begin{array}{l}\text { riool } \\
\text { /ri'ol/ }\end{array}$ & $\begin{array}{l}\text { riviER 'river' } \\
\text { /ri'vir/ }\end{array}$ \\
\hline 5. & $\begin{array}{l}\text { Konijn 'rabbit' } \\
\text { / ko'ncin/ }\end{array}$ & $\begin{array}{l}\text { Tonijn 'tuna' } \\
\text { / to'ncin/ }\end{array}$ & $\begin{array}{l}\text { koniJN } \\
\text { / ko'nein/ }\end{array}$ & $\begin{array}{l}\text { kONING 'king' } \\
\text { / ko'nin/ }\end{array}$ \\
\hline 6. & $\begin{array}{l}\text { Rusland 'russia' } \\
\text { /'roslant/ }\end{array}$ & $\begin{array}{l}\text { HoLland 'id.' } \\
\text { /'holant/ }\end{array}$ & $\begin{array}{l}\text { rusland } \\
\text { /'roeslant/ }\end{array}$ & $\begin{array}{l}\text { russin } \\
\text { 'russian (fem.)' } \\
\text { /'rosin/ }\end{array}$ \\
\hline
\end{tabular}




\begin{tabular}{|c|c|c|c|c|}
\hline 7. & $\begin{array}{l}\text { superman 'id.' } \\
\text { /'sypərman/ }\end{array}$ & $\begin{array}{l}\text { spiderman 'id.' } \\
\text { /'spaidərman/ }\end{array}$ & $\begin{array}{l}\text { superman } \\
\text { /'sypərman/ }\end{array}$ & $\begin{array}{l}\text { supermarket } \\
\text { 'íd.' } \\
\text { /'sypərmarkt/ }\end{array}$ \\
\hline 8. & $\begin{array}{l}\text { KIPpenvlees } \\
\text { 'chicken' } \\
\text { /'kipənvles/ }\end{array}$ & $\begin{array}{l}\text { GEItenvlees } \\
\text { 'goat meat' } \\
\text { /'ycitənvles/ }\end{array}$ & $\begin{array}{l}\text { kippenvleEs } \\
\text { /'kipənvles/ }\end{array}$ & $\begin{array}{l}\text { kippensoeP } \\
\text { 'chicken soup' } \\
\text { /'kıpənsup/ }\end{array}$ \\
\hline 9. & $\begin{array}{l}\text { voorkant 'front' } \\
\text { /'vorkant/ }\end{array}$ & $\begin{array}{l}\text { zIJkant 'side' } \\
\text { /'zcikant/ }\end{array}$ & $\begin{array}{l}\text { voorKANT } \\
\text { /'vorkant/ }\end{array}$ & $\begin{array}{l}\text { VoordEUR } \\
\text { 'front door' } \\
\text { /'vord } \phi r /\end{array}$ \\
\hline 10. & $\begin{array}{l}\text { HANDdoek } \\
\text { 'towel' } \\
\text { /'handuk/ }\end{array}$ & $\begin{array}{l}\text { sPandoek } \\
\text { 'banner' } \\
\text { /'spanduk/ }\end{array}$ & $\begin{array}{l}\text { handDoEK } \\
\text { /'handuk/ }\end{array}$ & $\begin{array}{l}\text { handREM } \\
\text { 'hand brake' } \\
\text { /'hantrem/ }\end{array}$ \\
\hline
\end{tabular}

Table 1. Stimulus words used in the experiment. Words were read with accent on the first or second syllable as indicated by bolded small capitals suggesting sub-word contrasts. Items 1 through 5 are non-compounds, i.e. simplex nouns or inflected verb forms (item 3). The last five items are compound nouns. All items have the stress (prosodic head, indicated by ${ }^{\prime \prime \prime}$ ) on the first syllable, except items 4 and 5 which have regular stress on the super-heavy final syllable.

The word triplets were inserted in a fixed carrier phrase which put the members in pairwise metalinguistic narrow-focus contrasts at the syllable level as exemplified in (5b) above for English. Dutch examples are given in (7a), where the contrast is between different first syllables (where the contrast happens to be on in the non-head first syllables), and in (7b), (with contrasts in the second syllable, which are also the prosodic heads of the words).

(7) a. ik bedoel 프ool, niet 프ool

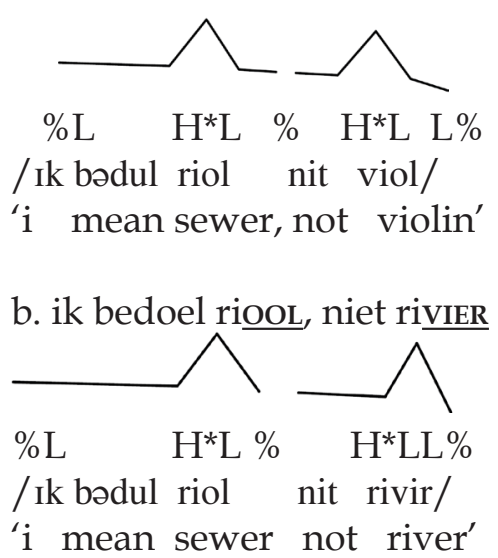

The 10 a-pairs (with narrow-focus contrast on the first syllable/morpheme) and the corresponding $10 \mathrm{~b}$-pairs (with contrast on the second syllable/morpheme) 
were printed on sheets of paper in normal Dutch orthography but with the contrasted syllables bolded and in small capitals, with a comma separating the first and second part of each sentence, as exemplified in (7a-b).

The materials were read by a male native speaker of Standard Dutch $(\mathrm{ABN})$, that is the first author, in a sound-insulating booth and digitally recorded $(44,1 \mathrm{KHz}, 16 \mathrm{bit})$ through a Sennheiser MKH 416 unidirectional condenser microphone. The speaker produced a natural speech pause between the first and second part of each utterance, corresponding with the comma in the orthographic representation of the sentences, realized each accent with a $\mathrm{H}^{*} \mathrm{~L}$ pitch configuration, and started and terminated each sentence with a low boundary tone, namely $\% \mathrm{~L}$ and $\mathrm{L} \%$, respectively. ${ }^{2}$ The pause indicated by the comma was not melodically marked.

Using Praat speech processing software (Boersma and Weenink 1996) the first (ik bedoel X) and second parts (niet $Y$ ) of the (a) and (b) sentences were cross-spliced, yielding the (c) and (d) versions, respectively, such that the accent patterns on the two contrasted words were no longer pragmatically coherent:

c. ik bedoel 프ool, niet rivieR

d. ik bedoel riool, niet viool

A stimulus series was then prepared with 40 trials. Each trial consisted of a pair of sentences one of which was pragmatically coherent (that is an a-version or a b-version), the other was the incoherent counterpart (those are the c-version and the d-version respectively). The order of the coherent and incoherent sentences was evenly balanced over the stimulus set and varied within the pairs at random. There was a 1-second pause between the two sentences within the pair, and a 5-second pause separating trials. After every tenth trial, a beep was sounded to help listeners keep track on their response sheets.

\subsection{LISTENERS}

Twenty-six listeners participated in the experiment. Thirteen of them were native speakers of Indonesian, who had learned Dutch as a second language. Four were Indonesian students at Leiden University with a length of residence (LOR) in the Netherlands between one and three years. One was from Kalimantan, one from Sulawesi, and two from Java. Their command of Dutch was poor to modest. A second group of Indonesian learners of Dutch comprised five female archivists who were enrolled in the TANAP project at Leiden University. ${ }^{3}$ These learners had been enrolled in an intensive course

2 Intonation transcription symbols conform to the ToDI (Tones of Dutch Intonation, Gussenhoven, Rietveld, and Terken 1999) conventions. For a concise survey of these conventions see Rietveld and Van Heuven (2009: 426-429).

3 TANAP:Towards a New Age of Partnership is a Dutch, Asian, South-African programme of cooperation to preserve the VOC archives as a component of the mutual heritage of the three continents and to create awareness of their importance among the parties concerned. 
of Dutch as a Second Language during three weeks immediately before the experiment. Four more Indonesian speakers of Dutch participated. These had LORs in the Netherlands between 5 and 27 years. Three of them were instructors at the Department of Languages and Cultures of South-East Asia and Oceania at Leiden University, and one was a professional linguist.

A group of thirteen native speakers of Dutch served as controls. These were ten adult students at Leiden University and three academically educated professionals (one was in fact the Dutch-language instructor of the TANAP group). All listeners had self-reported normal hearing and participated on a voluntary basis. They served with no financial compensation.

\subsection{PROCEDURE}

The experiment was conducted in seven sessions, with variable numbers of listeners per session. Listeners filled in a questionnaire on their (linguistic) background, specifying their gender, region of birth, language of the parents, age, length of residence in the Netherlands, and Dutch-language experience.

Listeners then received standardized written instructions, in English, to listen to the stimulus trials to be presented, and to decide for each pair of sentences within a trial whether they thought the first or the second utterance was the preferred, more coherent, reading. On the response sheets, the two sentences that made up each trial were spelled out in normal Dutch orthography, in the order in which they appeared in the stimulus presentation, so that intelligibility would not be a concern. Listeners were told to tick either the first or the second sentence per trial, with forced choice.

The stimuli were played back to the listeners through Quad ESL 63 Electrostatic loudspeakers in a medium-sized lecture room with some soft paneling attached to walls and ceilings in order to reduce reverberation. Four practice trials preceded the actual stimuli, the presentation of which took less then ten minutes.

\section{RESULTS}

We will first examine the overall results. Figure 1 shows the percentages of correct decisions made by the native Dutch listeners and by the Indonesian learners of Dutch. A listener's decision was considered correct if s/he had indicated on the response sheet that the coherent member of the sentence pair (that is an a-version or b-version) was the preferred reading. When the incoherent reading (a c-version or a d-version) was selected as the preferred choice, or when no response was given at all (in spite of the instruction), the decision was counted as an error. In figure 1, the percentages of the correct decision are arranged from poorest to best listener, for the two listener groups separately.

The results show quite clearly that, overall, the native Dutch listeners make correct decisions more often (83\%) than the Indonesian learners $(57 \%)$. The difference between the two groups is highly significant by a repeated-measure 
Analysis of Variance with native language (Indonesian versus Dutch) as a between-subjects factor and type of sub-word contrast (syllable level versus morpheme level) and position of the contrasted element (first versus second syllable/morpheme) as a within subjects factors, $\mathrm{F}(1,24)=22.9(\mathrm{p}<0.001)$.

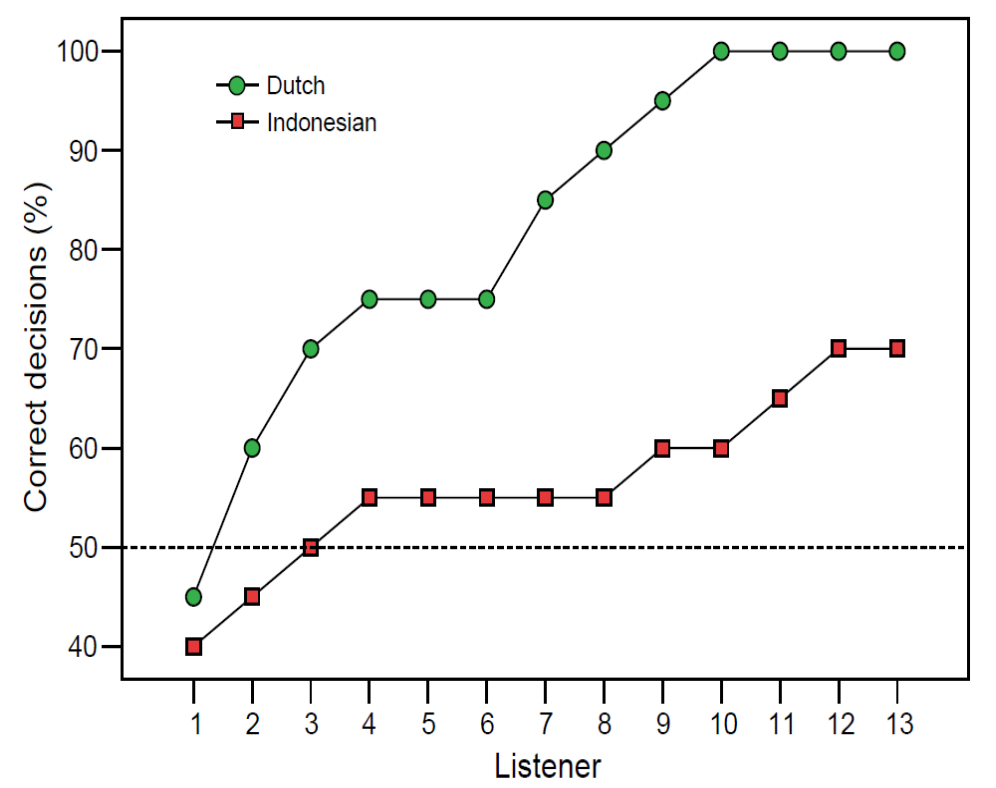

Figure 1. Percent correct decisions broken down by listener group (squares: Indonesian learners of Dutch; circles: native Dutch listeners). Within each group listeners are arranged from left to right from poorest to best.

Given the binary nature of the decision, chance is at $50 \%$. Using a binomial test, individual scores have to be in excess of $75 \%$ (15 correct out of 20 ) in order to be significantly better than chance ( $p=0.021$, one-tailed). Based on this criterion, not a single Indonesian learner performed better than chance. Within the native Dutch control group, three out of 13 listeners performed at chance level; the other ten were above chance and four even obtained a perfect score.

The results also show a bias favoring the member with the contrast in the first element over the member with the contrast on the second member. For the Indonesian learners the bias is 64 versus $49 \%$ correct for accent on the first versus second element. For the native Dutch controls, the percentages are at 87 and 78, respectively. The overall bias is highly significant by the RM-ANOVA, $\mathrm{F}(1,24)=14.5$ ( $\mathrm{p}=0.001)$. The bias may be due to at least two different - though interrelated - causes. First, most of the words used in our experiment had their prosodic head (stressed syllable) on the first syllable or morpheme. Second, just as in English (Cutler and Carter 1987), the majority of the monomorphemic words in the Dutch language are stressed on the first syllable (Van Heuven and Hagman 1988). Our listeners may have been biased 
towards utterances in which the accent-lending pitch configuration coincided with the prosodic head at the word level, that is, utterances with the most frequent position of accent and word stress.

Half of the trials contained a sub-word contrast between morphemes, the other half of the trials contrasted syllables that were meaningless in themselves. The effect of this factor is small and completely insignificant $F(1,24)<1$, with metalinguistic contrasts between morphemes being only slightly more difficult (68\% correct) than contrasts between meaningless syllables (70\% correct). The results, however, differ markedly between the Indonesian learners and the native Dutch controls. Morpheme contrasts are easier than syllable contrasts for the native listeners ( 85 versus $80 \%$ correct), whilst the reverse is the case for the nonnative listeners (52 versus $61 \%$ correct, respectively). The interaction between type of contrast and listener group falls only just short of significance, $\mathrm{F}(1,24)=4.1(\mathrm{p}=0.055)$.

A summary of the results is given figure 2, which shows percent correct decisions for native Dutch listeners (left panel) and for Indonesian learners (right panel) broken down by type and position of contrasted element.
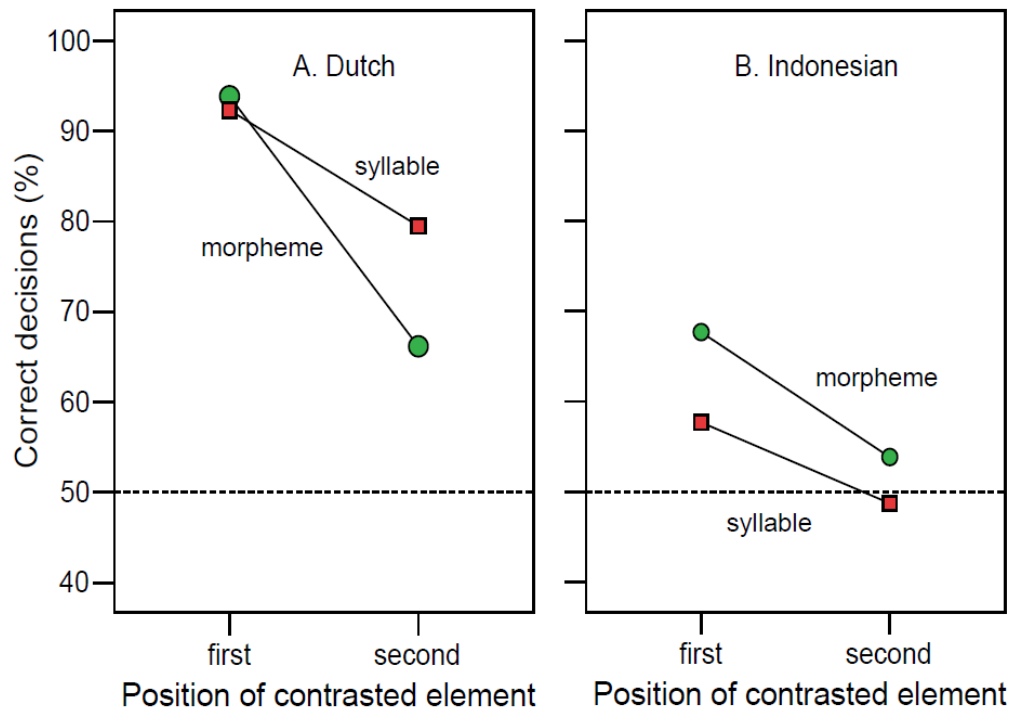

Figure 2. Percent correct decisions broken down by type (meaningless syllables $=$ circles versus morphemes $=$ squares $)$ and position (first or second element in word) of contrast, for native Dutch listeners (left panel A) and for Indonesian learners of Dutch (right panel B)

A last issue we deal with is the effect of length of residence on the learning of the Dutch mechanism of sub-word contrast marking through accentuation. Obviously, this part of the analysis only makes sense when the listeners are foreign learners. Figure 3 displays the percentage of correct decisions as a function of the LOR of our Indonesian learners. Note that some learners had to be assigned the same LOR, as they came to the Netherlands as a group to take part in an intensive Dutch (reading) course (see above). 


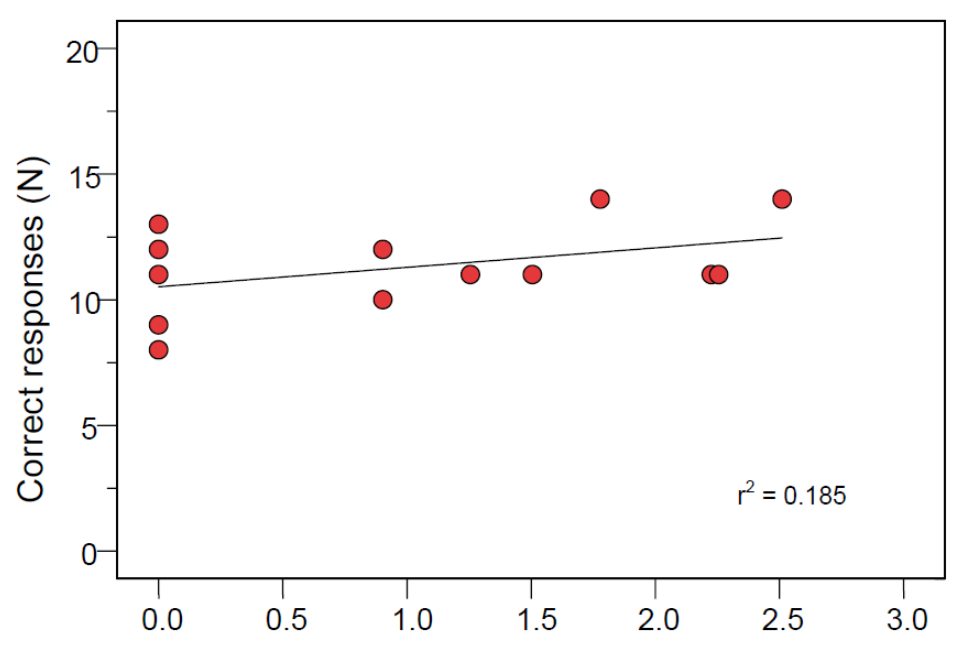

Length of residence in the Netherlands (log months)

Figure 3. Number of correct decisions by Indonesian learners of Dutch as a function of Length of Residence (plotted logarithmically) in the Netherlands

There is just a slight tendency for test performance to increase with length of residence. The correlation coefficient $(\mathrm{r}=0.430, \mathrm{p}=0.070$, one-tailed $)$ is rather small and just fails to reach statistical significance. ${ }^{4}$

\section{CONCLUSION AND DISCUSSION}

In this article we have tested the hypothesis that Indonesian learners of Dutch find it very difficult, if not impossible, to use variable accent positions in words as a cue to pragmatic contrasts, of a meta-linguistic nature, below the level of the word. Their inability to use this feature of Dutch (and English) follows from the circumstance that their first language, namely Bahasa Indonesia, has no word stress. If in a language any syllable in a word may be prominent as long as there is just one prominent syllable per (content) word - without any communicative consequence, as seems to be the case in Indonesian, the speakers of such a language will not be sensitive to differences in accent position within words.

The results of our experiment allow us to draw a few conclusions. First, and foremost, the results show unambiguously that Indonesian learners of Dutch are insensitive to narrow-focus contrasts below the word level, just as predicted. Although some Indonesians do a little better than their fellow compatriots, no Indonesian learner used the narrow-focus accent

4 Length of Residence (LOR) was expressed as the logarithm of the number of months the subject had spent in The Netherlands rather than the number itself. The correlation with $\log$ LOR was slightly better than with linear LOR. Learning curves are typically logarithmic (asymptotic) so that the present finding is only to be expected. 
cues at a better-than-chance level. One learner had spent over 27 years in the Netherlands and still he has not caught on to this specific property of the Dutch accentuation system. Moreover, no effect (only a trend at best) could be shown for the learners' ability to use narrow-focus in sub-word contrasts to increase with length of residence. This fits in with the finding that even the learner with the longest LOR did not perform above chance-level.

It should be realized that the incidence of sub-word contrasts in Dutch (and similar languages) is low. Situations in which meta-linguistic corrections are needed, hardly ever arise. It is therefore not surprising that Indonesian learners never caught on to the Dutch system of marking sub-word contrasts through narrow-focus accents. The surprising fact is that native Dutch listeners know how to deal with these phenomena, even though they may have been confronted with examples only a few times in their life. We believe that the correct interpretation of the sub-word narrow-focus contrasts falls out as a natural by-product of the prosodic system of Dutch. If a language has contrastive stress at the word level and uses accentuation to mark constituents for focus at the sentence level, then the default consequence is that the system is also used at the sub-word level to mark metalinguistic corrective focus. If this generalization is correct, languages that do not satisfy the conditions stipulated, should not be able to use narrow focus below the word level. Indonesian has no word stress, and only reluctantly, marks focus at the phrase-level; speakers of Indonesian do not know how to deal with sub-word contrasts. In similar vein, we predict that native speakers of French, which has fixed stress on the phrase-final syllable and is reluctant to use accent to mark focus at the sentence level (French prefers circumscriptions with syntactic means to mark constituents for focus, for example, C'est [Jean] qui l'a fait, lit. 'It is [John] who has done it', that is '[JOHN] has done it'), will find it difficult to deal with sub-word narrow-focus contrasts.

Our second conclusion is somewhat more problematic. Our results show that some Dutch native listeners do not use the accent cues to the full extent. Although the native control listeners performed much better than chance, on average, and were much better at using the accent cues than the Indonesian learners, there were three out of thirteen native Dutch listeners, who performed at chance level just as the Indonesian learners did. It may have been the case that our experimental task was too difficult for some of our listeners. Indeed, the task is fairly complex, requiring listeners to listen to two compound sentences, and then deciding which of the two sentences is pragmatically more felicitous. In hindsight an easier and more straightforward task could have been imposed on the subjects. One possibility might have been to present the four versions of each sentence (versions a through d) in isolation (at different points in the stimulus order) and ask the listeners to simply rate each utterance in terms of correctness or pragmatic acceptability. Dutch native listeners should have no problems with such a rating task.

A last point we may want to consider is what Indonesian has to gain by not having word stress. Generally linguists like to believe that all languages are equal and optimal as vehicles for human communication, although different 
languages have reached their optimality in different ways. If a language has word stress, and stands to gain from this property but at the same time it incurs a loss. Conversely, if a language chooses to go without stress, it will forgo certain benefits but will also be able to avoid the negative side-effects of having stress. As we see it, Indonesian has accent at the phrase level but does not have word stress. As a consequence, a word in Indonesian will be prominent if somewhere within the confines of that word there is an accentlending pitch movement. This movement is free to rove over the syllables that make up the word. This obviously removes the burden from the language learner to store the stress pattern of the words in his lexicon or to derive stress rules during the language learning process. For the listener, having to stress simplifies the word recognition process in that he does not have to check if the stress he hears matches the internal (mental) specification of the word as stored in the lexicon. The downside of not having stress is that the hearing a particular stress pattern does not help to narrow down the pool of word recognition candidates in the on-line processing of speech, nor can stress help as a post-lexical check on the correctness of provisional recognition decisions made. This state of affairs fits in with the general characterization of Indonesian as a 'massively underspecified language'.

One may suggest at this point that Indonesian fails to make good use of the absence of word stress and always uses accentuation to cue contrasts at the syllable level. After all, Indonesian might well have used a system whereby placing an accent on a particular syllable would always indicate to the listener that that syllable is communicatively important. It should be realized, however, that such a system would no longer be able to mark whole words as communicatively important. When a language has no stress, it can use accent in only way: it may use accent to mark syllable as important, but then it says nothing about the information status of the word as a whole; alternatively, the language may choose to mark words (and larger domains) as being in focus but when any syllable in the word may carry the accent, it does not impart any special information status to this syllable.

On the basis of this reasoning we would argue that the results of our experiment lend additional credibility to our claim that Indonesian is one of the - presumably rare (see introduction) - languages that have a word-prosodic system with neither stress nor tone.

\section{REFERENCES}

Boersma, P. and D. Weenink. 1996. "Praat, a system for doing phonetics by computer". [Report of the Institute of Phonetic Sciences 136, University of Amsterdam.]

Chun, D.M. 2002. Discourse intonation in L2; From theory and research to practice. Amsterdam: John Benjamins.

Comrie, B., M.S. Dryer, M. Haspelmath, and D. Gil (eds). 2005. World Atlas of Language Structures. Oxford: Oxford University Press.

Cutler, A. and D.M. Carter. 1987. "The predominance of strong initial syllables 
in English vocabulary", Computer Speech and Language 2: 133-142.

Cutler, A. and C.E. Clifton. 1984. "The use of prosodic information in word recognition", in: H. Bouma and D.G. Bouwhuis (eds), Attention and performance X, pp. 183-196. Hillsdale NJ: Erlbaum.

Cutler, A. and W. van Donselaar. 2001. "Voornaam is not (really) a homophone; Lexical prosody and lexical access in Dutch", Language and Speech 44: 171-195.

Ebing, E.F. 1997. Form and function of pitch movements in Indonesian. Leiden: CNWS. [CNWS Publications 55.]

Heuven, V.J. van. 1988. "Effects of stress and accent on the human recognition of word fragments in spoken context; Gating and shadowing", in: W.A. Ainsworth and J.N. Holmes (eds), Proceedings of the Seventh FASE/Speech-88 Symposium, pp. 811-818. Endinburgh: The Institute of Acoustics.

Heuven, V.J. van. 2008. “Making sense of strange sounds: (mutual) intelligibility of related language varieties; A review", International Journal of Humanities and Arts Computing 2: 39-62.

Heuven, V.J. van and P.J. Hagman. 1988. "Lexical statistics and spoken word recognition in Dutch", in: P. Coopmans and A. Hulk (eds), Linguistics in the Netherlands 1988, pp. 59-68. Dordrecht: Foris.

Heuven, V.J. van, L. Roosman, and E. van Zanten. 2008. “Betawi Malay word prosody", Lingua 118: 1271-1287.

Ladd, R.D. 1996. Intonational phonology. Cambridge: Cambridge University Press.

Langeweg, S.J. 1988. The stress system of Dutch. PhD thesis, Leiden University.

Odé, C. 1994. "On the perception of prominence in Indonesian", in: C. Odé and V.J. van Heuven (eds), Experimental studies of Indonesian prosody, pp. 27107. Leiden: Vakgroep Talen en Culturen van Zuidoost-Azië en Oceanië, Leiden University. [Semaian 9.]

Rasier, L. and P. Hiligsmann. 2007. "Prosodic transfer from L1 to L2; Theoretical and methodological issues", Nouveaux cahiers de linguistique française 28: 41-66.

Remijsen, B. 2002. "Lexically contrastive stress accent and lexical tone in MaÈya", in: C. Gussenhoven and N. Warner (eds), Laboratory phonology VII, pp. 585614. Berlin/New York: Mouton de Gruyter.

Remijsen, B. and V.J. van Heuven. 2005. "Stress, tone and discourse prominence in the Curaçao dialect of Papiamentu", Phonology 22: 205-235.

Rietveld, A.C.M. and V.J. van Heuven. 2009. Algemene fonetiek. Bussum: Coutinho.

Roosman, L.M. 2006. Phonetic experiments on the word and sentence prosody of Betawi Malay and Toba Batak. Utrecht: LOT. [LOT dissertation series 129.]

Sluijter A.M.C. and V.J. van Heuven. 1995. "Effects of focus distribution, pitch accent and lexical stress on the temporal organisation of syllables in Dutch", Phonetica 52: 71-89.

Sluijter A.M.C. and V.J. van Heuven. 1996. "Spectral balance as an acoustic correlate of linguistic stress", Journal of the Acoustical Society of America 
100: 2471-2485.

Zanten, E. van and R.W.N. Goedemans. 2007. "A functional typology of Austronesian and Papuan stress systems", in: V.J. van Heuven and E. van Zanten (eds), Prosody in Indonesian languages, pp. 63-88. Utrecht: LOT. [LOT Occasional Series 9.]

Zanten E. van, R.W.N. Goedemans, and J.J.A. Pacilly. 2003. "The status of word stress in Indonesian", in: J. van de Weijer, V.J. van Heuven, and H.G. van der Hulst (eds), The phonological spectrum; Volume II: Suprasegmental structure, pp. 151-175. Amsterdam/Philadelphia: John Benjamins.

Zanten, E. van and V.J. van Heuven. 1998. "Word stress in Indonesian; Its communicative relevance", Bijdragen tot de Taal-, Land-and Volkenkunde 154: 129-147.

Zanten, E. van and V.J. van Heuven. 2004. "Word stress in Indonesian; Fixed or free?", NUSA; Linguistic Studies of Indonesian and other Languages in Indonesia 53: 1-20. 